\title{
Herpes intraoral recidivante
}

\author{
Recurrent intraoral herpes \\ Diviana Gómez Morones, ${ }^{\star}$ Miguel Padilla Rosas, ${ }^{\ddagger}$ Mario Nava Villalba, ${ }^{\S}$ \\ Ana Elizabeth Sánchez Becerra,§ Juan Manuel López Salvio』
}

\section{RESUMEN}

El herpes intraoral recidivante es una de las manifestaciones ocasionadas por una infección recurrente por herpes virus simple 1 (HVS-1) y en menor grado por herpes virus simple 2 (HVS-2). La infección primaria por HVS suele darse en la infancia y en su mayoría es asintomática, por lo que el individuo desconoce que presenta la infección. La lesión más frecuente por herpes recurrente es el herpes labial y en menor porcentaje las lesiones intraorales, las cuales se manifiestan como vesículas que después se rompen y se unen para formar úlceras en mucosa queratinizada. Se ha encontrado relación entre el HVS y otras patologías bucales como el eritema multiforme (EM) y enfermedades periodontales. El diagnóstico para las lesiones recurrentes puede basarse en las manifestaciones e historial clínico pudiendo apoyarse de estudios de laboratorio. El tratamiento suele limitarse al alivio de síntomas, por lo que resulta efectivo el uso de enjuagues bucales y analgésicos.

Palabras clave: Herpes recurrente, herpes intraoral, gingivoestomatitis.

\section{INTRODUCCIÓN}

Los herpes virus son de tipo ADN pertenecientes a la familia herpesviridae, de la cual se pueden identificar el virus herpes simple 1 (HVS-1) y el tipo 2 (HVS-2), así como el virus varicela zóster, virus Epstein-Barr, citomegalovirus,

\section{ABSTRACT}

Recurrent intraoral herpes is one of the manifestations caused by a recurrent infection of herpes virus simplex 1 (HSV-1) and less common by herpes simplex 2 (HSV-2). The primary infection by HSV usually occurs in childhood and is mostly asymptomatic therefore the individual does not know that presents the infection. The most common lesion by recurrent herpes is labial herpes and in lower percentage intraoral lesions, which manifest as vesicles that later break down and coalesce to form ulcers in keratinized mucosa. A relationship has been found between HSV and other oral pathologies such as erythema multiforme (EM) and periodontal diseases. The diagnosis of recurrent injuries is generally based on clinical manifestations and medical records and can be supported by laboratory tests to confirm the diagnosis. The treatment is usually limited to relieve the symptoms, which is why mouthwashes and analgesics are effective.

Keywords: Recurrent herpes, intraoral herpes, gingivoestomatitis.

virus herpes humano tipo 6 (HHV-6), tipo 7 (HHV-7) y el tipo 8 (HHV-8). ${ }^{1,2}$

Las infecciones por virus herpes simple ocasionan lesiones vesiculares en piel y mucosa, el HVS-1 se manifiesta principalmente en mucosa bucal, así como en ojos, piel y cara, mientras que el HVS-2 se da en área genital

\footnotetext{
* Pasante de la Licenciatura en Cirujano Dentista, Departamento de Clínicas Odontológicas Integrales.

* Profesor de carrera, Departamento de Clínicas Odontológicas Integrales.

$\S$ Profesor de carrera, Departamento de Microbiología y Patología.

I Estudiante de la Maestría en Patología y Medicina Bucal.
}

Universidad de Guadalajara, Centro Universitario de Ciencias de la Salud.

Recibido: 01 de septiembre de 2020. Aceptado: 10 de enero de 2021.

Citar como: Gómez MD, Padilla RM, Nava VM, Sánchez BAE, López SJM. Herpes intraoral recidivante. Rev Mex Periodontol. 2021; 12 (1-3): 30-33. https:// dx.doi.org/10.35366/102956 
mediante el contacto sexual; ${ }^{1}$ sin embargo, un pequeño porcentaje de lesiones orales se le atribuyen al HVS-2 debido al contacto orogenital siendo indistinguibles de las lesiones por HVS-1. ${ }^{3}$ Ambos virus se caracterizan por causar una infección primaria y una infección secundaria o recurrente, la infección primaria es en la cual el individuo seronegativo se expone por primera vez al virus, ocasionando una infección sistémica, la cual puede ser sintomática o asintomática, ocurriendo a edad temprana, por lo general antes de los cinco años de edad. ${ }^{1,4}$

La transmisión del virus puede ser tanto por lesiones activas como por fluidos corporales, ${ }^{3}$ teniendo una incubación de tres a nueve días. ${ }^{1}$ Se estima que 95\% de la población mundial a la edad de 49 años ya ha sido infectada por HVS-1. ${ }^{5}$

Una vez establecida la infección primaria, sólo un pequeño porcentaje manifiesta síntomas, principalmente erupciones vesiculares en cualquier sitio de la mucosa oral, la cual se denomina gingivoestomatitis herpética primaria, además de fiebre, dolor de cabeza y linfoadenopatía cervical. Una vez que se manifestaron los síntomas, el virus viaja al ganglio trigeminal donde permanece latente. ${ }^{3,6}$

La infección secundaria o recurrente es básicamente la reactivación del virus latente, en la cual el virus viaja desde el axón a la periferia para producir una infección a nivel de las células epiteliales superficiales al liberar proteínas virales. ${ }^{6,7}$

La reactivación del virus se da en $20-40 \%$ de los pacientes que tuvieron una infección primaria, ${ }^{8}$ dicha reactivación puede ser desencadenada por luz ultravioleta, estrés, calor, frío, alergia, trauma o cambios hormonales. ${ }^{1,2}$

La infección recurrente se manifiesta principalmente en el sitio donde fue la inoculación primaria, el área más común es el borde del bermellón y piel adyacente, cuya manifestación se conoce como herpes labial, las lesiones intraorales son menos frecuentes, se limitan en su mayoría a mucosa queratinizada, las cuales comienzan como vesículas de 1-3 $\mathrm{mm}^{1}$ que después se rompen y se unen para dejar úlceras recubiertas con fibrina que desaparecen a los 10-14 días sin dejar cicatrices siendo una manifestación característica. ${ }^{8}$ Dichas lesiones se clasifican dentro del grupo de lesiones gingivales no inducidas por placa dentobacteriana de origen viral. ${ }^{4}$

En pacientes inmunocomprometidos, las lesiones pueden presentarse de manera atípica, aumentando la duración y rapidez de progresión de las lesiones. ${ }^{7}$

La mayoría de los pacientes tienen signos prodrómicos como dolor, sensación de ardor, hormigueo o comezón, durante este periodo las secreciones tienen gran potencial de contagio. ${ }^{1,6}$
Las lesiones intraorales por una infección por herpes recurrente suelen presentarse en mucosa adherida, las cuales deben ser diferenciadas de las lesiones ocasionadas por úlceras aftosas, las cuales se presentan en mucosa móvil. Existe evidencia de que la presencia del HVS-1 altera la respuesta inmunológica del periodonto, influyendo directamente en el desarrollo de enfermedad periodontal, ${ }^{2}$ ya que el virus se ha detectado en periodontitis, gingivitis y en gingivitis necrosante. ${ }^{4}$ Además, se ha encontrado relación entre el HVS-1 y el eritema multiforme (EM), se ha demostrado que cerca de $70 \%$ de casos de eritema multiforme han sido asociados con una reactivación sintomática de HVS-1 ${ }^{1-3,8}$ al encontrar antígenos de HVS-1 en lesiones por EM. ${ }^{9}$

El diagnóstico puede establecerse con base en la presentación y antecedentes clínicos, además de estudios como citología exfoliativa, cultivo y biopsia, siendo la citología exfoliativa la de elección debido a que para poder realizar el cultivo se requiere sustraer líquido de una vesícula intacta, lo cual es extremadamente raro en las lesiones intraorales. ${ }^{1,8}$

Las lesiones por HVS-1 son autolimitantes, sin embargo, el tratamiento con antivirales puede ser efectivo si se administra oportunamente, siendo el aciclovir el más efectivo en lesiones mucocutáneas, se ha demostrado que la clorhexidina sola o en combinación con aciclovir puede tener efectos antivirales en lesiones intraorales. Si el paciente experimenta dolor de larga duración es aconsejable la prescripción de AINES, como ibuprofeno, ${ }^{1-3}$ también se recomiendan soluciones como difenhidramina a un 5\%, enjuagues con solución salina y bicarbonato de sodio. ${ }^{4}$

\section{DESCRIPCIÓN DEL CASO CLÍNICO}

Mujer de 34 años que acude a consulta de la maestría en Patología y Medicina Bucal de la Universidad de Guadalajara, por presentar dolor de tipo urente en la zona de la encía del paladar, a la exploración clínica se observan úlceras secundarias (refiere que inicialmente eran vesículas) las cuales iniciaron seis días antes de acudir a consulta. Al interrogatorio, reporta que tuvo hace una semana un cuadro de faringoamigdalitis aguda con fiebre cuantificada de 39.8 grados, presencia de pus sobre las amígdalas, odinofagia y adenomegalias bilaterales en la zona lateral del cuello. Acudió al médico, el cual le prescribió antibiótico, a los tres días los síntomas orofaríngeos habían cesado; sin embargo, refiere que aproximadamente al segundo día de haber iniciado el cuadro de dolor amigdalino tuvo una sensación de dolor muy intenso de EVA 8, de tipo urente en la zona de la encía palatina del lado derecho, describe 


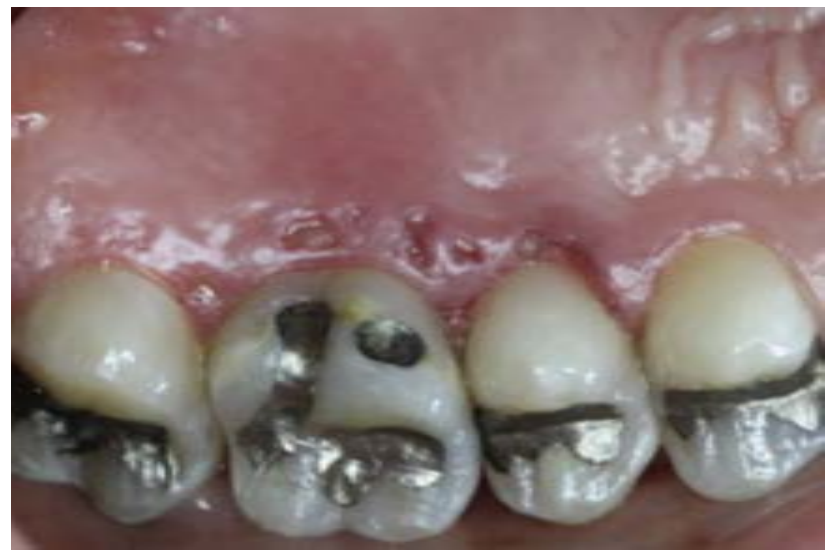

Figura 1: Se observan úlceras en encía libre y adherida palatina de O.D. 14-17.

que era ampollas que con el cepillo de dientes reventó aumentando la sensación de dolor. A la exploración clínica se observan úlceras de tipo secundario en la zona de la encía libre y adherida palatina de los OD 14, 15, 16 y 17 (Figura 1), la paciente refiere dificultad para comer y para su higiene bucal. Al interrogatorio afirma haber padecido herpes labial recurrente, con esta información más los hallazgos encontrados en la exploración física concluimos que se trata de herpes recurrente intraoral.

Se le dio indicaciones de colocación de clorhexidina en gel $0.12 \%$ sobre las úlceras, consumir líquidos y alimentos fríos, evitar alimentos calientes e irritantes y cita de seguimiento en 10 días. A los 10 días regresó completamente asintomática, a la exploración física las úlceras habían sanado en su totalidad apoyando el diagnóstico de reactivación intraoral por herpes virus (Figura 2).

\section{DISCUSIÓN}

El HVS es un virus neurotrópico, de los cuales el HVS-1 y el HVS-2 tienen manifestaciones orofaciales y genitales. ${ }^{9}$ El HVS-1 infecta en mayor medida la región orofacial causando gingivoestomatitis primaria, herpes labial y en menor grado manifestaciones intraorales cuando se trata de una infección recurrente. ${ }^{1,2}$

Las infecciones por HVS-1 comienzan por una infección primaria, que en la mayoría se presenta de manera asintomática, sólo de 10 a 12\% de los niños infectados presentan signos y síntomas, por lo que nuestro paciente está fuera de rango de esa edad. ${ }^{9}$

Cuando se presenta la primoinfección son lesiones sintomáticas, por lo general se manifiesta como gingi- voestomatitis acompañada de fiebre, dolor de cabeza y linfoadenopatía cervical. ${ }^{3,6}$ Las lesiones intraorales deben ser diferenciadas de úlceras aftosas, eritema multiforme y gingivitis ulceronecrosante. ${ }^{9}$

Después de la infección primaria, el virus queda latente y puede ser reactivado de manera espontánea o desencadenada por traumatismo, exposición solar o estrés. La reactivación del virus puede manifestarse como herpes labial o herpes intraoral, siendo esta última menos común. ${ }^{1-3,9}$

Las lesiones intraorales recurrentes aparecen, en su mayoría, en mucosa queratinizada como úlceras pequeñas y dolorosas que sanan en siete a 14 días sin dejar cicatriz, tal como se presentó en nuestro caso, ${ }^{9}$ dichas lesiones suelen confundirse con úlceras aftosas, por lo que es importante que el personal estomatológico tenga conocimiento sobre la presentación de ambas entidades, así como de sus demás posibles diagnósticos diferenciales, ya que esto influirá en el tratamiento de elección.

El diagnóstico para las lesiones por HVS puede realizarse únicamente mediante la presentación y antecedentes clínicos, por lo que realizar una anamnesis a fondo resulta de gran importancia.

Los estudios de laboratorio son de mayor utilidad en casos en los que el cuadro clínico sea atípico, como en pacientes inmunocomprometidos en los que los signos y síntomas se ven agravados. ${ }^{7,9}$

Al tratarse de una infección autolimitante, el tratamiento puede ser únicamente sintomático mediante la administración de analgésicos, enjuagues con solución salina o enjuagues antimicrobianos, siendo la clorhexidina el de elección debido a que ha demostrado tener efectos antivirales. ${ }^{1,3,4}$

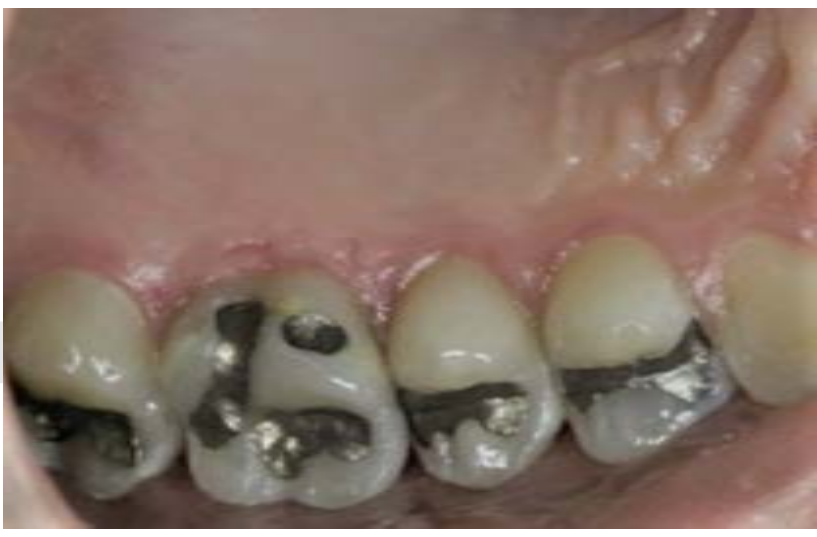

Figura 2: Se observa cómo a los 10 días las úlceras han sanado en su totalidad. 


\section{CONCLUSIÓN}

Las manifestaciones clínicas intraorales de la infección por el HVS son muy específicas, conocerlas nos beneficia en la buena praxis de nuestra labor diagnóstica.

\section{REFERENCIAS}

1. Neville B, Damm D, Allen C, Chi A. Oral and maxillofacial pathology. 3rd ed. Missouri: ELSEVIER; 2009, 240-247.

2. Ballyram R, Wood NH, Khammissa RAG, Lemmer J, Feller L. Oral diseases associated with human herpes viruses: aetiology, clinical features, diagnosis and management. S Afr Dent J [Internet]. 2016 [cited 11 July 2020]; 71 (6): 253-259. Available in: http:// www.scielo.org.za/scielo.php?script =sci_arttext\&pid =S001185162016000600006\&lng=en

3. Regezzi JA, Sciubba JJ. Oral pathology: clinical pathologic correla-

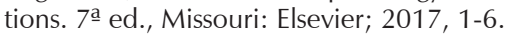

4. Salinas M, Yuni J, Millán I, Ronald E. Gingivoestomatitis herpética primaria: conducta odontológica. Acta Odontol Venez [Internet]. 2008 [citado 8 Jul 2020]; 46 (2): 219-226. Disponible en: http://ve.scielo.org/scielo.php?script=sci_arttext\&pid=S0001$63652008000200022 \& \operatorname{lng}=\mathrm{en}$
5. James C, Harfouche M, Welton NJ et al. Herpes simplex virus: global infection prevalence and incidence estimates. Bull World Health Organ [Internet]. 2016 [cited 8 July 2020]; 98 (5): 315-329. Available in: https://www.who.int/bulletin/volumes/98/5/19-237149/en/

6. Sapp JP. Patología oral y maxilofacial contemporánea. 2a ed. España: Elsevier; 2005, 200-203.

7. Bascones-Martínez A, Pousa-Castro X. Herpesvirus. Av Odontoestomatol [Internet]. 2011 [citado 11 Jul 2020]; 27 (1): 11 24. Disponible en: http://scielo.isciii.es/scielo.php?script $=$ sci arttext\&pid $=$ S0213-12852011000100002\&lng =e

8. Lindhe J, Lang N, Karring T. Periodontología clínica e implantología odontológica. 5ta ed. Buenos Aires: Médica Panamericana; 2005.

9. Arduino PG, Porter SR. Herpes Simplex Virus Type 1 infection: overview on relevant clinico-pathological features. J Oral Pathol Med. 2008; 37 (2): 107-121. Available in: https://pubmed.ncbi. nlm.nih.gov/18197856/

Correspondencia: Miguel Padilla Rosas

E-mail: miguelpadilla_rosas@hotmail.com 